\title{
Observar as crianças para integrar saúde e educação
}

\section{Observe the children to integrate health and education}

Damaris Gomes Maranhão é Professora Doutora da Universidade de Santo Amaro e do Instituto Vera Cruz;

Tatiana Melo Santos, Fabiana Santos Rodrigues Coimbra, Debora Renata Clemente e Elaine Matos Barros são enfermeiras do Centro de Formação Profissional e Educacional (CEDUC).

Contato: damarisgomesmaranhao@gmail.com

\section{Resumo}

Documentos e programas reiteram a necessária integração dos cuidados com saúde e educação da primeira infância. 0 objetivo deste estudo foi integrar as perspectivas de profissionais da saúde e da educação na análise de elementos facilitadores e/ou dificultadores do processo de construção do protagonismo da criança no cuidado de si e do outro. Trata-se de um estudo observacional e de análise de vídeos, com foco nas cenas de cuidados com as crianças de cinco creches. Observar o protagonismo da criança no processo de cuidado mediado pelo professor e as brincadeiras de cuidado entre as crianças evidenciou-se como uma eficaz estratégia formativa e de ampliação do olhar de profissionais de campos complementares para integrar saúde e educação. Palavras-chave: cuidado da criança, educação infantil, saúde, integralidade em saúde.

\section{Abstract}

Documents and programs reassert the necessary integration of health care and education in early childhood. This study pursues an integration of perspectives of health and education professionals when analyzing elements 
which facilitate and/or hamper the construction process of role of care in children, of both care of themselves and of other children. This is an observational study based on videos' analysis, focused on caring scenes inside five daycare centers. The observation of the child's role in the caring process mediated by the teacher and of some plays among children involving care proved to be an effective training strategy, also capable of expanding the vision of professionals from complementary fields in order to integrate health and education.

Keywords: child care, child rearing, health, integrality in health.

\section{Introdução}

Organizações sociais e programas governamentais têm reiterado a necessária integração de políticas públicas para a promoção do desenvolvimento na primeira infância. Embora todos concordem com o princípio segundo o qual o binômio cuidar-educar é indissociável, observa-se, no cotidiano dos serviços, uma organização de trabalho que o fraǵmenta. Há ainda muita dificuldade de interlocução entre profissionais de campos diferentes, apesar de apresentarem os mesmos objetivos: 0 desenvolvimento integral e saudável da criança.

Conforme Houzel escreveu em crônica publicada na Folha de S.Paulo, em 14 de maio de 2014: "Nosso cérebro, órgão do corpo responsável pela concretização dos pensamentos formulados, expressos e observáveis em linguagem, comportamentos e em produções culturais, é incapaz de observar ao mesmo tempo o todo e as partes".

Por outro lado pode-se argumentar que a percepção humana, como outras funções intelectuais superiores, também é construída em um processo histórico e sociocultural. Para aprofundar o conhecimento sobre um fenômeno foi necessário fazer recortes, fragmentá-lo e depois sintetizá-los para possibilitar uma nova percepção.

A síntese sobre o conhecimento dos objetos complexos pode ser elaborada em dois níveis: uma síntese paradigmática no âmbito de cada campo científico e uma síntese transdisciplinar construída na prática transitiva dos agentes científicos particulares (ALMEIDA FILHO, 1997).

0 problema é que profissionais de campos específicos trabalham lado a lado, atendendo a mesma criança, a mesma família, o mesmo grupo, mas, às vezes, sem compreenderem direito a lógica 
e intenção que orientam o foco e as prioridades de cada setor, o que pode resultar em conflitos de orientação. A limitação de nossa percepção como humanos a que a crônica de Houzel se refere de forma clara também é uma limitação que orienta o interesse e a percepção de profissionais de campos diferentes, uma vez que seu conhecimento foi construído por meio de recortes e fragmentação dos objetos complexos em cada cultura de especialistas (ALMEIDA FILHO, 1997).

Teorias, conceitos e classificações criadas pela linguagem, ensinadas e aprendidas em um campo de atuação específico, podem limitar a percepção sobre como a criança aprende e se desenvolve.

Retomando Houzel, uma possibilidade é "brincar" de alternar o olhar ora para as partes, ora para o todo, para depois integrar as perspectivas. Outra recomendação para ampliar a percepção e o conhecimento sobre o cuidado humano em sua interface com a saúde e a educação seria empregar a metodologia da antropologia social: tomar como ponto de partida a posição e o ponto de vista do outro (DAMATTA, 1987).

Esse foi o desafio de um grupo de profissionais que trabalhavam em creches mantidas e situadas em empresas: observar e estudar o processo de cuidado humano a partir do ponto de vista da criança, de sua interação com o professor e nas perspectivas dos profissionais de saúde e de educação (SANTOS et al, 2013).

\section{Objetivo}

Integrar as perspectivas de profissionais da saúde e da educação na análise de elementos facilitadores e/ou dificultadores do processo de construção do protagonismo da criança no cuidado de si e do outro.

\section{Metodologia}

Estudo observacional e de análise de cenas de cuidados com as crianças de cinco creches. As cenas compõem a documentação pedagógica e do acervo para formação dos profissionais das creches, que foram selecionadas a partir de critérios que atendiam os objetivos do estudo, como documentar situações de cuidados como alimentação, banho, lavagem de mãos e brincadeiras "de cuidar". As creches são mantidas por empresas situadas em municípios diferentes, localizados no raio de até $100 \mathrm{~km}$ da cidade 
de São Paulo, para atender os filhos e filhas de trabalhadores com cargos de operários, administrativos e gerenciais. As creches são administradas por uma mesma empresa especializada em educação infantil responsável pelo projeto pedagógico. Atendem crianças entre 6 meses e 4 anos de idade durante 8 a 10 horas diárias.

A análise foi realizada primeiro pelas enfermeiras de cada unidade responsável pela seleção e descrição das cenas. Em uma segunda etapa o material foi trocado entre elas, complementandose a análise. Em uma etapa final o material foi analisado conjuntamente com os professores, coordenadores pedagógicos, nutricionistas e lactaristas que participaram das cenas e com outros que compõem a equipe das creches.

As categorias de análise foram os comportamentos, mímicas, movimentos, falas, gestos e posturas das crianças que evidenciassem como elas se sentiam, compreendiam, participavam dos cuidados e como os incluíam em suas brincadeiras. Também foram observados e analisados os fatores que colaboravam ou dificultavam o protagonismo da criança conforme os seguintes indicadores: a organização do espaço e das condições deste para a participação da criança; a interação do professor com a criança e vice-versa, observável pela troca de olhares, mímicas, gestos, entonação da voz e palavras; o ritmo do processo de cuidado articulado com outras ações cotidianas; as atitudes e os procedimentos que facilitavam ou dificultavam a participação da criança; a segurança e o bem-estar da criança e dos profissionais durante os procedimentos.

0 referencial teórico que orientou a análise ancora-se em perspectiva sócio-histórico-dialética, na qual o contexto das situações, das ações e dos fatos integra os próprios fatos, as ações e as situações (MACHADO, 2004).

\section{Aspectos éticos}

Considerando os aspectos éticos, os critérios de seleção foram cenas do arquivo de documentação pedagógica que não expusessem a criança a constrangimentos, considerando que elas se expressam por outras linguagens além da verbal. Os responsáveis pelas crianças (mães ou pais), profissionais e empresas autorizaram a captação e o uso das imagens para a documentação pedagógica que já é parte do fazer cotidiano dos envolvidos no processo assim como para sua análise em trabalhos científicos e apresentação em eventos ou publicações, com a finalidade de aprimoramento do cuidado e da educação infantil. 


\section{A observação das crianças em processo de cuidado}

A rede de creches incluía uma enfermeira em cada unidade, que participava da formação da equipe e do suporte às famílias e aos professores relativos aos cuidados específicos com a saúde das crianças (MARANHÃO;MACHADO;CHECCINATTO, 2008)

Nos meses que antecederam este trabalho, as enfermeiras, os coordenadores pedagógicas e os gestores das unidades estudaram conjuntamente as teorias sobre o desenvolvimento humano para integrar perspectivas do campo da saúde com as da educação. Entre outras teorias considerou-se a perspectiva sócio-histórica do desenvolvimento humano na qual o estudo de um aspecto isolado da vida psíquica não faz sentido (MACHADO, 2004). Ao final desse processo, as enfermeiras foram convidadas a apresentarem aos profissionais das creches, na sua maioria professores, em um seminário, suas reflexões sobre a prática à luz das teorias estudadas, articulando saúde e educação.

Considerando que o tema geral do seminário seria o protagonismo da criança, elas planejaram estudar como as crianças participavam dos cuidados de seu corpo e como os incluíam em suas brincadeiras. Embora o grupo partisse do pressuposto de que o cuidado permeia toda ação educativa com a criança na creche, intencionalmente o foco seriam os cuidados corporais: oferta de alimentos, banho, troca de fraldas, higiene das mãos e brincadeiras das crianças que imitavam ou representavam esses cuidados.

Nessas unidades, a documentação em vídeos e fotos já é uma prática dos profissionais, com objetivo de elaborar a documentação pedagógica, relatórios avaliativos sobre as crianças e, a partir deles, planejar os trabalho pedagógico e empregá-los para reflexão sobre a prática no processo de educação continuada em serviço de toda a equipe.

As enfermeiras também empregavam esse tipo de registro para formar os professores, mas com foco nos procedimentos de banho, troca de fraldas, higiene de mãos e outros cuidados pelos quais eram responsáveis para promover o conforto, o bem-estar e a segurança das crianças.

Dessa vez elas foram desafiadas a olharem não apenas para os procedimentos, mas para expressões, reações, gestos, falas, postura corporal e interações das crianças com os professores ou com outras crianças durante os cuidados e brincadeiras "de cuidar", ou jogos de papéis (OLIVEIRA, 2011). A ideia não era julgar 
se o procedimento estava correto ou não, conforme o protocolo, mas como ele ocorria no cotidiano, a partir do ponto de vista da criança, o que seria analisado a partir de suas formas de expressão em cada idade.

\section{Resultados}

Cena 1: a interação de Carlos com a professora que o alimentava

A professora alimentava Carlos, de 7 meses, sentada à frente do cadeirão no qual ele estava sentado. Entre ambos, a superfície contendo o prato com a refeição. Ela segurava a colher com a papa e a oferecia a Carlos. Ela expressava, em sua face, uma mímica que antecipava os movimentos que esperava que ele fizesse: abria bem a boca, fazia movimentos de fechá-la ao colocar a colher em sua boca. A professora funcionava com um espelho para a criança, que imitava a mímica facial dela e, ao mesmo tempo, esboçava um sorriso. Ela falava: "Que delícia, que delícia de sopa", "Mastiga", "Eu sei que está gostoso!". Carlos movimentava seus braços e pernas, levando o braço direito em direção à professora e ao prato. Nesse momento em que o lactente quase alcançava o prato, a professora segurava suavemente seu braço direito na altura do cotovelo, impedindo-o de alcançar o prato e, em sua impulsividade, entorná-lo. Após a primeira colher de alimento colocada em sua boca, Carlos ficava parado. A professora dizia: "É gostosa"; a criança reagia iniciando os movimentos de mastigação e deglutição. Ao oferecer água no final da refeição, a professora esperava que ela deglutisse o líquido antes de oferecer outro gole. Ficavam evidentes, durante o processo de alimentação desse bebê, uma rica interação e a sintonia expressa por mímica, gestos e sons entre Carlos e a professora, embora esta contivesse o braço dele. Ela fez essa contenção talvez para evitar o que previu como risco de ele se sujar, de se queimar ou entornar o prato.

Analisando a cena, em primeiro lugar da perspectiva nutricional, pode-se considerar a atitude da professora adequada, uma vez que ela possibilitou alimentar a criança com segurança e afetividade. Ao observar a cena da perspectiva do protagonismo da criança, de seus movimentos, de sua participação, refletiu-se com o grupo sobre o que orientava a ação da professora ao conter o braço de Carlos.

Ao observar a mesma cena da refeição como um meio de desenvolvimento da criança, mediado pelo professor que a alimentava, pode-se iluminar a análise com base em um exemplo 
clássico do surgimento do gesto de apontar pelo bebê, realizado por Vygotsky:

\footnotetext{
Vygotsky mostra como um movimento do corpo da criança na direção de um objeto que está fora de seu alcance vai se transformar, especificandose e simplificando-se a partir da intervenção de um adulto que atribui à criança a intenção de pegar o objeto, e o entrega a ela - ou seja, atribui significado ao gesto da criança. O movimento, que consistia em um impulso de todo o corpo da criança, com braços estendidos e movimentos das mãos sugerindo o querer agarrar o objeto, passa, mais ou menos gradualmente, a ser um braço estendido com o dedo indicador apontado para o objeto e o olhar passeando entre este e a pessoa presente no ambiente. 0 movimento de pegar torna-se o ato de apontar. (CARVALHO et al., 2012, p. 72).
}

A integração de olhares de perspectivas teóricas complementares, da saúde e da educação possibilitou avaliar tanto as práticas relativas ao preparo dos alimentos (a combinação dos nutrientes na refeição, a porção e textura adequada ao processo digestório do bebê, a higiene, o ritmo, a rotina e o ambiente compatível com o atendimento coletivo) como também a ação educativa. Ao interagir com o adulto e compartilhar gestos, expressões, ações com o outro que o alimentava, Carlos desenvolvia habilidades, a comunicação e a consciência corporal em contraposição ao outro.

$\mathrm{Na}$ análise da cena com os profissionais das cinco creches que participaram da análise em uma segunda fase, abriuse a discussão para o grupo: o que facilitou ou dificultou o protagonismo da criança dessa idade?

0 grupo composto por professores, coordenadores pedagógicos, enfermeiros, nutricionista, gestores e lactaristas analisou que a professora, ao conter o braço do bebê, talvez com intenção de protegê-lo ou para evitar que entornasse o prato, dificultou uma ação conjunta. A reflexão continuou sobre os cuidados na oferta de uma refeição em ambiente coletivo e as oportunidades de participação de cada criança. A professora explica que era a primeira vez que ela lhe oferecia papa na creche e por isso optou por não oferecer-lhe a colher. A solução seria nomear para a criança o motivo da ação do professor? Oferecer um pouco de papa na mão do bebê? Oferecer outra colher para que ele tentasse manipulá-la, ainda que de forma "desajeitada"? Tolerar que sujasse sua mão na papa, desde que esta estivesse em temperatura adequada para não queimá-lo? 0 tempo previsto para alimentar todos os bebês seria suficiente para respeitar o tempo de cada um? 
A reflexão em grupo multidisciplinar sobre uma mesma cena, com diferentes olhares, contribui para que todos ampliem percepções e revisem conceitos e práticas.

0 professor precisa ter autonomia ao fazer a melhor escolha em cada momento, tendo em vista o protagonismo, a segurança e o bem-estar da criança, mas, para isso, é preciso que esteja consciente do que o leva a optar por uma ação ou outra.

Tolerar que um bebê coloque a mão na comida, "suje" o cadeirão, ou seu babador, participe mais ativamente da refeição, requer que se considerem as possibilidades de ordem e desordem que permeia o cuidado da criança (MARANHÃO, 2000).

Essa cena oferece um rico material para refletir sobre as possibilidades de alimentar o bebê no ambiente coletivo de uma creche, mantendo certa ordem que possibilite à criança, do ponto de vista nutricional, consumir o alimento preparado e oferecido no prato, em determinado horário e conforme sua capacidade digestiva em desenvolvimento. Ao mesmo tempo, há de se tolerar alguma desordem, no sentido de permitir que a criança participe da refeição sem tolher totalmente seus movimentos, uma vez que ela está transitando da fase impulsiva para a sensóriomotora, até adquirir as habilidades necessárias para sua gradativa independência em se alimentar.

Wallon (1979) escreve que as relações da criança com o meio começam com dominância emocional.

Os primeiros gestos que são úteis à criança não são gestos que Ihe permitirão apropriar-se dos objetos do mundo exterior ou evitá-los, são gestos dirigidos às pessoas, são gestos de expressão. E isto é muito importante, porque a humanidade é precisamente constituída por grupos onde os indivíduos têm em comum ritos, tradições, uma linguagem que lhes permite colaborar entre si tendo em vista dominar o mundo exterior, mas em primeiro lugar precisaram se apoiar uns nos outros, a fim de se auxiliarem mutuamente a subsistir (p. 201).

No entanto, nessa fase, já se constrói, pela mediação do outro humano, a etapa seguinte, que o autor denomina de "estádio sensório-motor".

A verdadeira manipulação, a exploração das formas, da estrutura, a decomposição das partes, seguida pela sua reunião, só aparecem no estádio sensório-motor, o qual principia por volta do oitavo ou décimo mês. Esta atividade investigadora diferenciada 
encontra-se ligada a todo um conjunto funcional próprio da espécie humana (WALLON, 1979, p. 61).

Uma questão muito presente nos processos de formação de professores, coordenadores e gestores de creche é a questão do tempo que o cuidado de um grupo de criança requer. Há um receio de que o cuidado atencioso, individualizado, conforme o ritmo de cada bebê, aumente o "tempo de espera" dos demais.

A hipótese das autoras é de que a qualidade da interação com a criança não está apenas no tempo concreto, mensurável e circunscrito pela rotina. A qualidade depende mais da consciência pelo professor do significado da construção de cada gesto pela criança nas ações conjuntas que o cuidado requer. Um exemplo disso é o banho de Davi, descrito a seguir, na mesma creche, e que tem um tempo de duração cronometrado no vídeo de 9 minutos, mas que nem por isso deixa de possibilitar uma rica interação entre ele e a professora.

\section{Cena 2: o banho de Davi}

A professora chegou ao trocador com Davi, 10 meses, em seus braços, sorrindo e falando: "Banho, banho, um banho bem gostoso". Davi foi colocado primeiro no bebê-conforto, que permaneceu no piso do banheiro para possibilitar que a professora organizasse a toalha, lavasse e enchesse a banheira e lavasse as mãos. Ao mesmo tempo que preparava o banho, ela falava com Davi, nomeando o que está fazendo. Depois, ao ensaboar seu corpo, nomeava cada parte ("Vamos lavar a barriga, as costas"), mas sempre de maneira afetiva e atenta à reação dele. Perguntava: "Cadê o pé?". Davi olhava para o próprio pé. A educadora lavava seus pés e pernas e, em seguida, direcionava o chuveirinho em direção às mãos dele: "Lava a mãozinha, lava". Davi batia palmas com a água escorrendo entre suas mãos. Estaria associando a expressão "bater as mãos", com uma das primeiras ações que os adultos ensinam aos bebês?

A necessidade e o desejo de decifrar o universo de significados que a cerca leva a criança a coordenar ideias e ações a fim de solucionar os problemas que se apresentam (MACHADO, 2004, p. 27).

A seguir a professora continuava, intencionalmente, convocando a criança a participar ativamente do banho: "Cadê sua mão? Que delícia, que gostoso!". Davi olhava para ela e para as próprias mãos. A educadora ajuda a criança a esfregar uma mão na outra e canta: "Lava uma mão, lava outra". Fala novamente para ele esfregar as mãos e depois sinaliza que o banho terminou. 
Ao enxugá-lo, a educadora pegou o pé dele e disse: "Olha o pé cheiroso, olha o pé cheiroso, põe o pé na boca". Davi segurava o pé e o colocava na boca. A educadora falava: "Ai, que delícia, é o pé!". Davi respondia: "Pé, é, é". Ela penteava o cabelo dele e pedia para que a ajudasse, dando-Ihe a escova na mão.

Refletir com as enfermeiras, os professores, os coordenadores e os gestores, a partir da observação da linguagem verbal e corporal estabelecida entre ambos, permitiu reavaliar as atitudes e os procedimentos do banho, além da higiene e do conforto. Semelhante à cena anterior, o banho constitui uma oportunidade de comunicação e de trocas afetivas com o bebê. A professora significa cada gesto, o instiga a participar, nomeia as sensações experimentadas pela imersão e massagem do corpo na água, ao enxugá-lo e vesti-lo.

Os cuidados corporais como o banho e a troca de fraldas requer um trabalho individualizado do professor com a criança e favorece uma troca afetiva pelo contato corporal reconfortante, essencial para o desenvolvimento saudável (CARVALHO, PEDROSA, ROSSETTIFERREIRA, 2012).

Ao mesmo tempo, foram avaliadas as possibilidades reais de interação e troca afetiva da professora com cada criança no contexto coletivo. Essa interação pode ser facilitada pela organização do espaço e pela técnica empregada para realizar o procedimento de forma segura e confortável, considerando a saúde do trabalhador e das crianças.

A professora precisa ser habilitada para o procedimentopadrão, não no sentido da interação com a criança, pois esta é individualizada e construída cotidianamente, no processo. 0 procedimento-padrão evita que a professora desvie o foco da atenção na relação com a criança para resolver problemas práticos como limpá-la sem contaminar a si mesma ou o colchonete com o cocô e onde descartar a fralda suja sem deixar a criança cair do trocador. Ela precisa estar habilitada para saber limpar o prepúcio de um menino ou a vulva de uma menina, como evitar ou cuidar de uma pele irritada pelos resíduos e registrar o observado. As enfermeiras colaboram na formação inicial, capacitando os professores e esclarecendo dúvidas relativas a esses procedimentos. A reflexão sobre a prática registrada em vídeos possibilita identificar falhas e aprimorar tanto o procedimento como a interação com a criança. Ela aponta também para a importância da integração de perspectivas dos coordenadores pedagógicos com as enfermeiras na formação inicial e continuada sobre o processo de cuidar. 
A análise conjunta, a partir de uma perspectiva histórica e dialética, conforme orienta-nos Vygotsky, é romper com as formas tradicionais de análise dos fenômenos (MACHADO, 2004, p. 27).

Cena 3: João ensina aos colegas a técnica e o motivo de ensaboarem as mãos

Antes do almoço, a professora acompanhou três meninos de aproximadamente 3 anos e 6 meses para lavar as mãos no banheiro da creche. Eduardo molhou as mãos e começou a laválas. João perguntou: "Onde eu lavo as mãos? Ele bateu palmas com as com as mãos ensaboadas, pressionando-as e esfregandoas. Falava em um tom como se estivesse ensinando os amigos e a professora: "Aqui também tem que passar, aqui também fede!'. Dirigia-se ao amigo Pedro: "Ó, Pedro, quando você lava a mão, você tem que passar do lado, assim ó (esfrega o local), sabe isso aqui ó (aponta) fede!'. Continuava a lavá-las observando o que os amigos estavam fazendo.

Pedro esticou a mão em direção à escova de dente que estava no suporte colado no espelho. A professora o continha e falava: "Agora não é hora de mexer com escova de dente! Já lavou sua mão?". João explicava para o colega: "É pra escovar os dentes, na hora da comida!".

As crianças dessa idade já adquiriram algumas habilidades para cuidar de si, embora algumas necessitem de ajuda da professora. Ficou evidente, nessa cena, que elas não aprendem apenas as técnicas, mas conceitos sobre o que é limpo e sujo, ou sobre a sequência dos cuidados, antes ou depois das refeições.

João emprega o termo "fede", que talvez tenha aprendido e associado à situação de higiene das mãos, com um sentido diferente, ou o empregou de forma genérica. Uma das interpretações possíveis é que, para ele, nessa idade, seja mais concreto o cheiro, o que "fede", do que a "sujeira", nem sempre aparente. Fica evidente a riqueza das interações que podem ocorrer no ambiente de um sanitário de creche.

No entanto, muitas vezes, com base no modelo tradicional de escola e de educação, as "salas de aula" são consideradas os únicos ambientes educativos. Mesmo que a professora, que está ocupada em dar conta de que todos usem o sanitário, limpemse, lavem as mãos antes da refeição, não perceba, as crianças interagem e "ensinam" umas as outras.

A observação e análise conjunta desses momentos permite conhecer como a criança pensa, assimila conceitos e desenvolve 
as habilidades, até se tornar independente para cuidar de si. Na perspectiva sóciointeracionista, aprendizagens, ensino e desenvolvimento são processos distintos mas que não existem de forma isolada.

A ação de conhecer se dá no movimento inter e intrapsicológico, no vaivém dialético entre os parceiros: na confirmação de objetivos comuns, no confronto de ideias, na busca de soluções, na competição, na cooperação (MACHADO, 2004, p. 31).

Cena 4: Ana e Clara compartilhando o cuidado das bonecas

Ana e Clara, de 1 ano e 6 meses, estavam sentadas em um colchonete, no qual havia uma almofada entre elas. Ana fazia movimentos com a mão sobre um cobertor que cobria uma boneca deitada no meio da almofada. Clara, que estava com uma boneca maior, parecia desejar colocá-la "para dormir" ao lado da outra. Ao tentar fazê-lo, Clara descobriu a boneca de Ana e tornou a cobri-la. Na segunda tentativa de Clara, Ana a ajudou a ajeitar a manta. Clara, embora conseguisse colocar a boneca ao lado da outra, pareceu mudar de ideia, retirando a menor com uma mão e a substituindo pela maior. Ana olhava para a professora, como se pedisse sua ajuda para intermediar o conflito. Esta falou com Clara: "Devolve o nenê para ela, Tatá". Clara falou algo que não foi possível entender no vídeo, mas pareceu apontar que agora o nenê de Ana foi o que colocou na almofada. A seguir, pegou a mamadeira que estava sobre o colchonete e começou a oferecer para boneca menor, que segurava no colo. Ana olhou a boneca deitada e a seguir para a professora que lhe respondeu: "Nana ele, cobre ele!". Ana disse: "Frio". A professora repetiu: "Cobre ele, está frio!". Ana cobriu a boneca e repetiu o movimento de antes, ninando-a com a mão. Clara continua a alimentar a outra boneca.

Analisando essa cena, observa-se que as meninas empregam gestos de cuidado, como cobrir, ninar, oferecer a mamadeira, imitando gestos vivenciados no próprio corpo ou reproduzidos a partir de uma imitação da professora ou de um familiar, realizando o mesmo cuidado com outra criança. Dessa forma, ela não apenas significa o que vivencia no momento e que parece evocar o vivido no próprio corpo ao ser cuidada pelo adulto, mas desenvolve habilidades e aprende o que o antropólogo Marcel Mauss denomina de "técnicas corporais", próprias de cada cultura (MAUSS, 2003).

A professora, ao oferecer brinquedos e um ambiente que possibilita o jogo de papéis, ou ao participar do imaginário da criança, pela mediação possibilitada pela presença discreta e 
observação atenta da brincadeira, faz intervenções pontuais, que ajudam a administrar um possível conflito entre as duas crianças e, ao mesmo tempo, dão suporte à ação, por meio da linguagem.

Em outra cena de jogo de papéis, com crianças mais velhas, observam-se dois meninos de aproximadamente 3 anos brincando em um ambiente que simula uma cozinha, contendo uma pia com torneira "de brinquedo". Um deles abriu a torneira. 0 outro, que a princípio estava fora da cena, trouxe uma garrafinha que simulava um detergente e a colocou sobre a mão do amigo, que a "ensaboou".

Observar as crianças brincando com as bonecas, fazendo-as dormir, alimentando-as, cobrindo-as, ou os meninos fazendo de conta que lavavam as mãos possibilita refletir sobre o significado do processo de cuidado vivenciado pelas crianças, em casa ou na creche.

Dessa forma, as crianças nos ensinam que o processo de cuidado é tão significativo para elas como seria outra brincadeira ou atividade considerada pelos adultos como "pedagógica".

\section{Considerações finais}

A metodologia de observação, captação e análise de cenas de cuidado, tendo como foco não apenas os procedimentos, mas também as expressões, interações e comportamentos das crianças, contribuíram para ampliar a percepção tanto dos enfermeiros como dos professores e de outros profissionais de uma rede de creches.

Embora essa metodologia seja uma prática empregada nos programas de educação continuada de professores que atuam na educação infantil, a maioria tem focado as ações educativas no stricto sensu em atividades desenvolvidas "em sala de aula", com raros estudos sobre as práticas de cuidados corporais.

Ao integrar, pela observação das crianças, os saberes que orientam a perspectiva dos profissionais de campos da saúde com os profissionais de educação possibilita-se a identificação de fatores que faliciltam ou dificultam o protagonismo no processo de cuidado. A interação com a criança e o seu protagonismo durante 
os cuidados corporais podem ser facilitados pela organização do espaço, pela técnica empregada para realizar o procedimento e, sobretudo, pelas atitudes dos professores, que para isso precisam estar atentos às expressões corporais, verbais e interesse das crianças em todos os momentos.

Este estudo possibilitou também o compartilhamento de uma estratégia formativa significativa, no sentido de alternar o olhar sobre o particular e o especifico de uma competência profissional com outro especialista que percebe a realidade da perspectiva orientada por outro campo de conhecimento.

As enfermeiras, os professores, as lactaristas, a nutricionista, os coordenadores e os gestores que observaram a participação da criança no cuidado de si, mediado pelo professor, em suas brincadeiras de cuidar, ampliaram as percepções e os conhecimentos que os orientavam, além do campo específico e à luz de uma perspectiva sócio-histórica.

\section{REFERÊNCIAS}

ALMEIDA FILHO, N. Transdisciplinaridade e saúde coletiva. Ciência e Saúde Coletiva, v. 11, n.1/2, 1997.

CARVALHO, A. M.; PEDROSA, M. I.; ROSSETTIFERREIRA, M. C. Aprendendo com a criança de zero a seis anos. Cortez: São Paulo, 2012.

DAMATTA, R. Relativizando: uma introdução à antropologia social. Rocco: Rio de Janeiro, 1987.

HOUZEL, S. H. O todo e as partes. Folha de S.Paulo [Internet]. 14 de maio de 2014. http://www1. folha.uol.com.br/colunas/suzanaherculanohouz el/2014/05/1460465-o-todo-e-as-partes.shtml>. Acesso em: 10 de outubro de 2015.

MACHADO, M. L. M. Educação Infantil e SócioInteracionismo. In.: OLIVEIRA, Z. M. R. Educação Infantil: muitos olhares. Cortez: São Paulo, 2004. p. 25-50. 
MARANHÃO D.G., MACHADO J.K., CHECCINATTO D. Cuidar e educar de bebês: desafios da mesma competência. In: Atem L.M. Cuidados no início da vida. Clínica, instituição, pesquisa e metapsicología. São Paulo: Casa do Psicólogo; 2008.

MARANHÃO, D. G. O cuidado como elo entre a saúde e educação. Cadernos de Pesquisa. São Paulo, n. 111, dezembro de 2000 .

MAUSS, M. As técnicas corporais. In.: MAUSS, M. Sociologia e antropologia. São Paulo: Cosac Naify, 2003. p. 401-22.

OLIVEIRA, Z. M. Jogo de papéis: um olhar sobre as brincadeiras infantis. São Paulo: Cortez, 2011.

SANTOS TM, COIMBRA FSR, CIEMENTE DRS, BARROS

EM, Cazarim PR, Maranhão DG. Construindo o olhar das enfermeiras sobre o protagonismo das crianças no processo de cuidado na creche. In.: Anais do I Seminário Internacional de Saúde da Criança, Adolescente e Família, XIV Encontro do Laboratório de Estudos Interdisciplinares em Família e Saúde, e o V Congresso de Enfermagem Pediátrica e Neonatal.

Gramado; 2013.

WALLON, H. Psicologia e educação da criança. Lisboa: Veja, 1979.

Recebido em: 14/10/2015.

Revisto em: 08/12/2015.

Aceito em:10/12/2015.

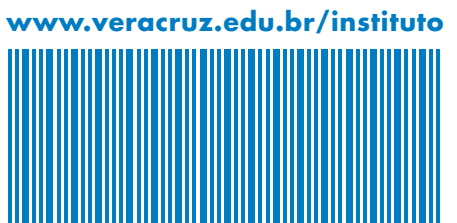

